\title{
A INSUFICIÊNCIA DA CONSTITUIÇÃO DE 1988 PARA INSTITUIR UM ESTADO DEMOCRÁTICO DE DIREITO: Uma Análise Empírica da Democracia Brasileira
}

http://dx.doi.org/10.21527/2176-6622.2018.50.38-49

Recebido em: $28 / 5 / 2018$

Aceito em: 13/9/2018

\section{Gustavo Cavalcanti}

Advogado inscrito na OAB.MG (no 155.263). Mestrando em Direito na Faculdade de Direito Milton Campos. Graduado em Direito pela Pontifícia Universidade Católica de Minas Gerais (2014). Técnico em Administração de Empresas (Sebrae-MG, 2009). Sócio fundador da Lern.com.br. Pós-graduando em Direito Público (IED/Fead). Professor voluntário de Empreendedorismo na Escola Profissionalizante Dr. Adolph Fritz. advgustavocavalcanti@gmail.com

\section{André Rubião}

Doutor em Ciência Política (Universidade Paris 8). Mestre em Filosofia do Direito (Universidade Paris 2). Mestre em Direito (Faculdade de Direito Milton Campos). Bacharel em Direito (PUC-Minas). Professor na Faculdade de Direito Milton Campos (FDMC), membro do Núcleo de Estudos sobre Gestão de Políticas Públicas (Negesp). Currículo lattes: <http://lattes.cnpq.br/4416971072504497>. Orcid: <http://orcid.org/0000-00020070-3641>.andrerubiao@hotmail.com

\section{RESUMO}

Objetiva-se neste artigo analisar de forma empírica a realização de paradigmas constitucionais de natureza democrática, relacionados à soberania popular e ao Estado de Direito, que permitem a instituição de um Estado Democrático de Direito. Inicialmente abordar-se-á o significado teórico da adoção constitucional do paradigma do Estado Democrático de Direito para, então, identificar de forma prática a realização deste paradigma na sociedade brasileira em relação a sociedades que já o fizeram. No contexto das pesquisas empíricas utilizadas identificamos lacunas que devem ser preenchidas para que o paradigma constitucional do Estado Democrático de Direito possa ser realizado no cotidiano social brasileiro.

Palavras-chave: Constituição. Democracia. Empirismo. Habermas. Brasil.

\section{THE INSUFFICIENCY OF THE 1988`S CONSTITUTION TO INSTITUTE A DEMOCRATIC STATE OF LAW: AN EMPIRICAL ANALYSIS OF BRAZILIAN DEMOCRACY}

\section{ABSTRACT}

The present article aims at empirically analysis the concretization of democratic nature constitutional paradigms related to popular sovereignty and rule of law, that lead to the institutionalization of a democratic state of law. Firstly, it will approach the theoretical meaning of constitutionally adopting a democratic state of law paradigm and then it identifies in paradigmatically mode the concretization of such paradigm over brazilian society in comparison with others that have already done it. At the empirical research context it identifies breaches that should be filled for the democratic state constitutional paradigm to be concrete over the brazilian everyday social life.

Keywords: Constitution. Democracy. Empirism. Habermas. Brazil.

\section{SUMÁRIO}

1 Introdução. 2 A Teoria da Democracia de Jurgen Habermas. 3 Análise Empírica das Variáveis que Possibilitam a Instituição de Estados Democráticos de Direito. 3.1 Uma Comparação Entre a Democracia Brasileira e Democracias de Fato. 3.2 Variáveis em que o Brasil é uma Democracia de Fato e Variáveis em que o Brasil Sequer é Considerado Como Democrático. 4 Conclusão. 5. Referências. 


\section{INTRODUÇÃO}

O Brasil instituiu o Estado Democrático de Direito em sua Constituição. ${ }^{1}$ Esse paradigma representa a superação do constitucionalismo clássico, calcado no Estado de Direito e na previsão de direitos considerados "humanos", posteriormente básicos, que se formou a partir das revoluções liberais, pela incorporação do epíteto do Estado Democrático de Direito, revelador de um anseio de conferir legitimidade aos direitos básicos, por meio da participação do povo na construção desses direitos.

A teoria crítica, aqui centrada na Filosofia e na Sociologia de Jurgen Habermas, apresenta elementos para superar a tensão existente entre os dois princípios basilares da democracia, Soberania Popular e Estado de Direito, que até então não se conciliavam na definição de qual dos dois seria responsável por legitimar a norma e o Direito.

Nesse sentido, Jurgen Habermas constrói a rearmonização destes princípios, de forma que o Estado Democrático de Direito se desenvolve na pressuposição recíproca, ou a partir da co-originalidade existente entre Soberania Popular e Estado de Direito. ${ }^{2}$

Da grassroots democracy, ${ }^{3}$ das iniciativas de empowerment ${ }^{4}$ e dos trabalhos precursores de Carole Pateman nos EUA, ${ }^{5}$ passando pelo "agir comunicativo" de Habermas ${ }^{6}$ e pela "razão pública" de Rawls, ${ }^{7}$ até as iniciativas de Peter Dienel ${ }^{8}$ e Ned Crosby $^{9}$ de resgatar o sorteio na política, havia um consenso no sentido de denunciar os limites da representação e de fazer com que a ação política se tornasse mais próxima dos cidadãos em um reconhecimento de que não se atinge uma democracia de fato com a mera existência de direitos e procedimentos legalmente previstos.

É importante destacar que esse novo paradigma não veio para negar as conquistas do anterior. Não se trata de recuperar a "liberdade dos Antigos" (no sentido positivo, de poder propor mudanças) em detrimento da "liberdade dos Modernos" (no sentido negativo, de se proteger dos abusos do Estado), mas de entender que os pilares do Republicanismo e do Liberalismo podem conviver numa nova teoria da sociedade. De fato, o que surge como um aparente conflito ${ }^{10}$ é solucionado por Habermas por meio da mútua pressuposição das autonomias públicas e privadas para a autocompreensão normativa da democracia constitucional (HABERMAS, 1996).

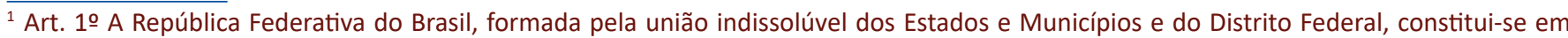
Estado Democrático de Direito e tem como fundamentos:

I - a soberania;

II - a cidadania;

III - a dignidade da pessoa humana;

IV - os valores sociais do trabalho e da livre iniciativa;

$\checkmark$ - o pluralismo político.

Parágrafo único. Todo o poder emana do povo, que o exerce por meio de representantes eleitos ou diretamente, nos termos desta Constituição.

2 Ver HABERMAS, 1996, p. 127.

${ }^{3}$ Ver FISCHER, 1993.

${ }^{4}$ Ver BERGER; NEUHASS, 1977.

${ }^{5}$ Ver PATEMAN, 1970.

${ }^{6}$ Ver HABERMAS, 1987.

7 Ver RAWLS, 1971.

${ }^{8}$ Ve: DIENEL, 1970.

${ }^{9}$ Ver CROSBY 1975.

10"If i may borrow a terminological shorthand from contemporary discussions in the United States, "liberal" traditions conceive human rights as the expression of moral self-determination, whereas "civic republicanism" tends to interpret popular sovereignty as the expression of ethical self-realization. From both perspectives, human rights and popular sovereignty do not so much mutually complement as compete with each other" (HABERMAS, 1996, p. 100).
} 
Esta pressuposição habermasiana nos leva a questionar o real significado de um país instituir um Estado Democrático de Direito. Como visto, o Brasil encontra-se constitucionalmente instituído como um Estado Democrático de Direito; a República Democrática do Congo, por sua vez, é um "Estado de Direito (...) social e democrático". ${ }^{11}$ Com base nas Constituições do Brasil e do Congo, o que se pode entender sobre cada um destes países e suas respectivas democracias?

Desta forma, torna-se necessária a elaboração de uma classificação que possa ser aplicada a países que constitucionalmente instituem Estados Democráticos de Direito, como o Brasil e o Congo, e países que constitucionalmente nada definem nesse sentido, como é o caso do Reino Unido e da Dinamarca. Nesse viés, falamos aqui de países que constitucionalmente apresentam-se como Estados Democráticos de Direito e países cujas Constituições são silentes quanto à adoção do paradigma do Estado Democrático de Direito. As democracias que constitucionalmente adotam o paradigma supramencionado serão classificadas como democracias de direito, ou seja, democracias reconhecidas, pelo menos no âmbito do sistema jurídico nacional.

Ocorre, no entanto, que o fato de um país não se enquadrar, juridicamente, como um Estado Democrático de Direito, não o impede de ser uma democracia de fato, classificação que será adotada para os países em que os princípios basilares da democracia se materializam no dia a dia dos cidadãos.

Assim, teremos, de um lado, democracias de direito, em que a instituição do regime democrático resume-se ao texto legal, e do outro, as democracias de fato, nas quais a instituição do regime democrático é real e materializada nas instituições e práticas sociais.

Torna-se necessário, então, para apresentarmos uma classificação exauriente, tratarmos dos países em que haja a adoção legal do regime democrático e este regime esteja materializado na vida dos cidadãos, o que seria a união das democracias de fato e de direito, aqui abordadas como democracias completas.

Nesse sentido, tratamos os países em três níveis: (i) democracias de direito, que se restringem ao texto legal, (ii) democracias de fato, que se materializam por meio de instituições e procedimentos democráticos, e (iii) democracias completas, nas quais a previsão legal do regime democrático encontra-se concretizada em instituições e procedimentos democráticos.

Desta forma, torna-se necessário estabelecer os requisitos que serão considerados para buscar identificar um país como uma democracia de direito, de fato ou completa, com o objetivo final de responder se o Brasil está respeitando a concretização equilibrada dos elementos contidos nos princípios da soberania popular e do Estado de Direito para que a adoção do paradigma constitucional do Estado Democrático de Direito possa ser percebida nas suas instituições e práticas sociais, podendo o país ser classificado como um democracia completa e não uma mera democracia de direito. Isso será feito a partir da análise dos relatórios produzidos pelo The Economist Intelligence Unit, por meio do Democracy Index 2017 e pelo Latinobarómetro, acerca da percepção que os cidadãos, o mercado, os analistas políticos e os leigos fazem da democracia. Dialogando com o quadro teórico habermasiano, levantamos diversas variáveis e categorias para estudar e comparar a democracia brasileira com outras democracias espalhadas pelo mundo, conforme Tabela 1.

A construção deste trabalho é metodologicamente separada em três momentos. Primeiramente será descrita parte da teoria do Direito e da democracia de Habermas responsável pela reconciliação entre soberania popular e direitos humanos, por meio das autonomias públicas e privadas, de forma a situar estes dois princípios como base para o estabelecimento de democracias de fato.

Este estabelecimento possibilitará que mergulhemos na prática democrática adotada nos mais diversos países, o que será feito tendo como norte as variáveis e categorias anteriormente descritas e que serão adequadamente explicadas na seção oportuna. Ao final, analisaremos com mais cuidado as questões empíricas da democracia brasileira objetivando identificar se a nossa constitucional democracia de direito concretizou-se podendo ser, agora, chamada de democracia completa.

${ }^{11}$ Ver Constituição da República Democrática do Congo, artigo 1‥ 


\section{A TEORIA DA DEMOCRACIA DE JURGEN HABERMAS}

O paradigma do Estado Democrático de Direito pode ser representado a partir de um levantamento histórico elaborado por Habermas (1985). Este levantamento almeja demonstrar o desenvolvimento do Estado Alemão, do imperialismo europeu até o welfare state a partir do Direito. Habermas elabora tal reconstrução histórica tendo como tema central ondas de juridification, ${ }^{12}$ que num total de quatro ondas históricas culminam na forma do Estado alemão contemporâneo. ${ }^{13}$

Tabela 1 - Variáveis e Categorias. A partir da soma das notas obtidas pelo país em cada uma das variáveis é possível situar o país em uma das quatro Categorias

\begin{tabular}{l|l} 
Variáveis: & Categorias:
\end{tabular}

\begin{tabular}{l|l}
\hline I. pluralismo e processo eleitoral & a) Democracias de fato \\
\hline II. liberdades civis & b) Democracias falhas \\
\hline III. funcionamento do governo & c) Regimes híbridos \\
\hline IV. participação política & d) Regimes autoritários \\
\hline V. cultura política & N
\end{tabular}

Fonte: Adaptado de THE ECONOMIST, 2017.

As três primeiras ondas de produção legislativa (juridification) possibilitam o surgimento do Constitucional Estado Democrático de Direito, a partir de normas legais capazes de garantir aos indivíduos o exercício simultâneo das suas autonomias públicas e privadas, por meio da Soberania Popular e do Estado de Direito, que configuram os dois pilares de sustentação da democracia deliberativa (HABERMAS, 1995, p. 15-16).

Habermas apresenta uma versão aceitável acerca da reconciliação entre autonomias públicas e privadas a partir do estabelecimento do seu Sistema de Direitos em um conjunto de cinco categorias ${ }^{14}$ de direitos básicos, em que a quarta categoria, uma categoria que se aplica reflexivamente ${ }^{15}$ a todas as outras quatro, define:

Direitos fundamentais à participação, em igualdade de chances, em processos de formação da opinião e da vontade, nos quais os cidadãos exercitem suas autonomias políticas e através dos quais eles criam direito/leis legítimo(as) (HABERMAS, 1996, p. 123).

Com o estabelecimento desta categoria de direitos, Habermas torna a democracia um direito básico do indivíduo, entendida esta como a possibilidade não de o indivíduo participar de procedimentos eletivos, mas sim e efetivamente, a possibilidade de o indivíduo participar da formação e da vontade política, criando, assim, os próprios indivíduos, os seus direitos de forma legítima.

\footnotetext{
${ }^{12}$ Habermas utiliza este termo para definir um aumento no número de processos de produção legislativa que pode ser distinguido entre processos de densificação da lei, em que a legislação se torna mais específica e apta a tratar casos individuais ao invés de relações genéricas, bem como processos de expansão legislativa, enquanto a produção de leis para regular situações que anteriormente não eram abarcadas pela legislação (Ver HABERMAS, 1985).

${ }^{13}$ Estes processos de juridification iniciam-se no período absolutista e após a primeira onda de produção de leis culmina no Estado Burguês, onde há o reconhecimento do indivíduo privado apto a ingressar em relações comerciais e que no âmbito destas relações deve ser protegido, uma vez que se reconhece a sua legitimidade para fazer parte desta interação comercial, o que se materializa no surgimento da sociedade civil. Do Estado Burguês, uma segunda onda de produção legislativa culmina no Estado Constitucional Burguês, em que a autoridade executiva passa a ser constitucionalmente regulada, de forma que os cidadãos passam a receber direitos subjetivos de ação contra o soberano que não aja no melhor interesse da coletividade, de forma que os direitos à vida, propriedade e liberdade passam a ser inerentes à condição do ser humano e não meras derivações do exercício da atividade comercial institucionalizada pela lei privada ou contratos. Esta segunda onda de produção legislativa possibilita o surgimento do Estado Constitucional Democrático, em um ambiente em que direitos básicos, materializados no "Estado de Direito", passam a ser acompanhados pela "soberania popular" enquanto possibilitou-se aos cidadãos o direito de participação política, ao lado daqueles direitos anteriormente garantidos. Ver: Habermas, 1985, 203-07.

${ }^{14}$ HABERMAS, 1996, p. 122-31

${ }^{15}$ HABERMAS, 1996, p. 123
} 
Como esta é uma categoria de direitos básicos que se aplica reflexivamente às demais categorias, tem-se que o exercício da autonomia privada, materializada nos direitos básicos (liberdade subjetiva igual à maior medida possível de liberdade, status de membro da comunidade e proteção judicial aos direitos eventualmente desrespeitados) somente será possível a partir do exercício da autonomia pública.

Esta autonomia pública, por sua vez, é a própria materialização da autonomia privada do indivíduo, o que torna possível o surgimento da ideia de cooriginalidade entre autonomia pública e privada, ou seja, que uma somente existe a partir da outra e isso de forma recíproca, ou seja, nenhuma existe sem a outra.

De um lado, baseado em Locke, tem-se a ideia de um Estado de Direito ou rule of law, que garanta a isonomia (liberdade de todo indivíduo ser governado apenas por leis que se apliquem igualmente a todos), a legalidade (os representantes do Estado somente podem fazer o que a lei permite) e os direitos individuais (garantias contra opressões por parte do Estado). De outro lado, com base em Rousseau, tem-se a Soberania Popular, que garante que todo poder político emana do povo, de forma que o governo será mantido e sustentado apenas com o consentimento e autorização da coletividade. $O$ desafio de Habermas, numa época em que o Liberalismo reivindicava a preponderância da autonomia privada e o Republicanismo defendia a prevalência da autonomia pública, foi desenvolver uma teoria capaz de conciliar o Estado de Direito com a Soberania Popular.

Nesse sentido, o Estado de Direito deve ser encarado como a configuração política que permite ao cidadão o exercício da sua liberdade e a constituição de propriedade. Isso lhe possibilita atuar livremente no mercado, protegido contra os mais ricos, os mais fortes e contra o próprio Estado, de forma que em troca dessa liberdade e do direito de propriedade, o Estado de Direito reivindicava o exercício de um soberano poder estatal. ${ }^{16}$ Esse modelo não pode então ser associado ao surgimento de códigos e leis escritas, e sim ao surgimento de limites a serem impostos em favor das garantias individuais, para que os cidadãos pudessem exercer sua autonomia privada numa sociedade mercantilista, livre dos abusos dos regimes absolutistas.

A construção destes direitos básicos, no entanto, não se mostrou suficiente para evitar abusos e aplicações inadequadas, fazendo-se necessário surgir uma nova onda de leis capazes de garantir ao cidadão mecanismos para que ele pudesse efetivar aqueles direitos que julgasse indispensáveis. Nesse contexto, surge a ideia de um Estado Constitucional Democrático, modelo capaz de efetivar a autonomia pública e a Soberania Popular, de modo que as leis possam contar com uma efetiva participação dos cidadãos (HABERMAS, 1985, p. 207). Este momento, chamado por Habermas de juridificação do procedimento legítimo, ${ }^{17}$ deve ser acompanhado não somente pelo reconhecimento da liberdade de se organizar e constituir partidos políticos, mas também pela institucionalização de mecanismos capazes de vincular a produção legislativa com a formação de um debate público, de modo que os destinatários das normas possam ter uma efetiva participação (HABERMAS, 1985, p. 207).

A soberania popular não se vincula mais de forma exclusiva com a ideia do sufrágio universal ou procedimentos em que prevalece a opinião da maioria. Agora ela está ligada à formação de um espaço público, capaz de oferecer condições para um agir comunicativo, de modo que as decisões tenham mais legitimidade.

Nessa busca de conciliação entre Estado de Direito e Soberania Popular, Habermas traz o exemplo do movimento feminista e da luta pelos direitos das mulheres. No marco das garantias individuais, foram importantes as conquistas das mulheres, tanto na equiparação dos direitos (por exemplo, o voto) como no reconhecimento de direitos especiais (como no caso da gravidez). Alguns desses direitos, no entanto, geraram distorções (como diferenças salariais no mercado de trabalho) e foram criticados por parte do movimento feminista. Habermas mostra então que não bastam os direitos individuais e tampouco uma soberania popular que definiu essas garantias para as mulheres. É preciso uma autocompreensão do papel da mulher na sociedade, por meio de um debate público e da elaboração de leis com mais legitimidade. Ou seja, para Habermas, não importa aquilo que deve sobressair ou vir primeiro (a autonomia privada, na visão dos liberais, ou a au-

\footnotetext{
16"The legal is supposed to guarantee the liberty and property of the private person, the certainty of the law, the formal equality of all legal subject before the law, and thereby the calculability of all legally normed action. On the other hand, public law authorizes a sovereign state power" (HABERMAS, 1986, p. 358).

${ }^{17}$ HABERMAS, 1985, p. 207.
} 
tonomia pública, na visão dos republicanos), porque no seu entendimento o poder popular de autodeterminação e as garantias individuais se entrelaçam, na ideia de cooriginalidade, validando-se e pressupondo-se reciprocamente (HABERMAS, 2002 p. 293-305).

Tendo em vista este quadro teórico, referente ao Estado Democrático de Direito, esta pesquisa pretende analisar variáveis que apontem para a presença de autonomia pública e privada nas democracias contemporâneas. Se, porém, levarmos em conta o pensamento de Habermas, não basta a presença formal (de direito) dessas garantias referentes à Soberania Popular e ao Estado de Direito. É necessária uma presença material (de fato) desses elementos, para que se possa falar num efetivo Estado Democrático de Direito.

\section{ANÁLISE EMPÍRICA DAS VARIÁVEIS QUE POSSIBILITAM A INSTITUIÇÃO DE ESTADOS DEMOCRÁTICOS DE DIREITO}

A pesquisa empírica utilizada neste trabalho, doravante denominada "ranking da democracia", foi produzida pelo The Economist Intelligence Unit, considerando 165 países e dois territórios ao redor do mundo, avaliando-os conforme as variáveis já apontadas na Tabela 1 e classificando-os conforme as categorias indicadas na Tabela $2 .^{18}$

Os números demonstram que $95,5 \%$ da população mundial não sabem o que é uma democracia de fato, embora possam viver em democracias de direito, tornando-se absolutamente relevante a classificação que separa o elemento jurídico do elemento empírico deste instituto. No que se refere ao elemento empírico, no entanto, este é analisado de acordo com as variáveis apontadas na Tabela 1.

Tabela 2 - Categorias utilizadas pelo ranking da democracia, quantos países foram classificados em cada categoria e o percentual da população que vive sob cada regime

\begin{tabular}{l|c|c} 
Categorias: & número de países & \% da população mundial \\
\hline a) Democracias de fato & 19 & 4,5 \\
\hline b) Democracias falhas & 57 & 44,8 \\
\hline c) Regimes híbridos & 39 & 16,7 \\
\hline d) Regimes autoritários & 52 & 34
\end{tabular}

Fonte: Adaptado de THE ECONOMIST, 2017.

As variáveis utilizadas para situar um país em uma das categorias antes elencadas possuem elementos que permitem um trânsito entre os conceitos originais de Estado de Direito e Soberania Popular, o que permite a sua vinculação ${ }^{19}$ à noção de cooriginalidade desenvolvida por Habermas para as autonomias privadas e públicas em seu "sistema de direitos", ${ }^{20}$ de forma que uma passa a pressupor a outra para a sua válida existência e, consequentemente, para a legitimidade e coercibilidade do "sistema de direitos", a partir da legitimidade das normas legais. ${ }^{21}$

\footnotetext{
${ }^{18}$ Importante mencionar que o The economist utiliza a nomenclatura "Democracia Completa" para designar as nações em que as variáveis se realizam satisfatoriamente. Para nós, uma democracia completa será aquela em que além da realização fática há a adequada previsão constitucional, razão pela qual chamammos democracias completas apenas aquelas em que há, ao mesmo tempo, uma democracia de fato e de direito.

${ }^{19} \mathrm{~A}$ introdução formulada pelo The Economist sobre as suas unidades de medida da democracia é forte na sintonia com a proposta habermasiana da cooriginalidade e pressuposição recíproca, embora não haja menção ao autor: "The five categories are interrelated and form a coherent conceptual whole. The condition of holding free and fair competitive elections, and satisfying related aspects of political freedom, is clearly the sine qua non of all definitions" (THE ECONOMIST, 2018 p. 62).

${ }^{20}$ Ver BAXTER, 2011, p. 129.

${ }^{21}$ Ver BAXTER, 2011, 61-106.
} 
Democracias de fato, assim, são compreendidas como países que respeitam as liberdades políticas e civis dos cidadãos, apresentando um funcionamento satisfatório do governo, meios de comunicação diversificados e independentes, além de um sistema judicial eficiente, cujas decisões são respeitadas e os problemas são mínimos em relação ao funcionamento das instituições (THE ECONOMIST, 2018, p. 64). Estas democracias são aquelas que possuem uma média superior a 8 pontos.

Democracias falhas, por sua vez, apresentam certo respeito às liberdades políticas e civis dos cidadãos, no entanto a participação política destes, o funcionamento do governo e o pouco desenvolvimento de uma cultura política impedem que estas democracias falhas se transformem em completas (THE ECONOMIST, 2018, p. 64). Estas democracias possuem nota média entre 6-8.

Já os regimes híbridos não são sequer classificados como democracias mínimas ou semidemocráticos. Eles apresentam falhas substanciais em seus procedimentos eletivos que os impedem de ser "livres e justos", o que revela o peso da autonomia política/pública do cidadão no processo de classificação de um país como democrático, mesmo que falho. Esses regimes apresentam ainda um frágil Estado de Direito, de forma que a sociedade civil não consegue criar e efetivar direitos básicos. Eles possuem também um Judiciário pouco ou nada independente, podendo haver perseguição aos meios de comunicação, mediante censura e assédio. Trata-se de regimes nos quais os problemas das democracias falhas agravam-se e tornam-se mais visíveis (THE ECONOMIST, 2018, p. 64). A nota média para este regime está entre 4-6.

Por fim, os regimes autoritários são majoritariamente associados às ditaduras ou aos regimes em que o pluralismo político é mínimo ou inexistente. Instituições democráticas até podem existir, com pouca ou mínima substância, mas os meios de comunicação são vinculados ao governo ou a grupos que se ligam a este. Além disso, abusos aos direitos civis são tolerados e críticos ao governo são censurados e repreendidos, inexistindo qualquer forma de Judiciário independente (THE ECONOMIST, 2018, p. 64). As notas desses regimes variam entre 0-4.

Dessa forma, adotando como pano de fundo a classificação introdutória de (i) democracias de direito, (ii) democracias de fato e (iii) democracias completas, concluímos que existe uma óbvia diferenciação entre democracias de fato e democracias de direito, de maneira que a existência desta última não permite a conclusão pela existência da primeira.

Como visto, a partir do empirismo que caracteriza democracias de fato, estas pressupõem a existência concreta de instituições e sistemas democráticos, perceptíveis e materializados no dia a dia dos indivíduos que materializam as essências buscadas por meio do estabelecimento dos princípios basilares da Soberania Popular e do Estado de Direito.

Nesse contexto, a inexistência prática das instituições que materializam estes princípios não pode ser suprida pela formalização legal-constitucional dos mesmos princípios em textos legais que criam democracias de direito mas falham em efetivar democracias de fato, ou completas, por não materializarem os pilares da democracia nas suas instituições sociais, tais como governo, poder Judiciário, processos políticos, liberdades civis e políticas.

Assim, temos como pano de fundo para a análise da realidade democrática do Brasil a existência de democracias de fato e de direito. Enquanto a primeira se destaca pela materialização dos pilares democráticos da Soberania Popular e do Estado de Direito na vida dos cidadãos, a segunda diferencia-se da primeira por prever, formalmente a existência destes mesmos pilares falhando, no entanto, em concretizá-los.

Há, ainda, aquelas que podem ser definidas como democracias completas, caso existentes de fato também o sejam de direito, ou vice-versa.

\subsection{Uma Comparação Entre a Democracia Brasileira e Democracias de Fato}

O ranking da democracia é dominado pelos países nórdicos, classificados como democracias de fato, ao passo que o Brasil encontra-se em 49ㅇ lugar, classificado como uma democracia falha (Tabela 3), ou seja, embora trate-se de uma democracia de direito, isso não o torna uma democracia de fato, conforme conclusão da seção anterior (THE ECONOMIST, 2018, p. 5-6). 
Uma análise da nota brasileira para o ano de $2017,6,86$ pontos, revela uma nota meio ponto menor do que há dez anos, quando o país obteve 7,38, ainda insuficiente para classificá-lo como democracia completa, mas certamente melhor do que a atual, o que permite o entendimento de que caminhamos em sentido oposto ao da democracia de fato, embora o nosso documento constitucional, nesse sentido, não tenha sido alterado neste mesmo período.

No ano de 2008 a nota brasileira manteve-se em 7,38, vindo, em 2010, a cair para 7,12, nota que se manteve até 2013 e subiu, no ano de 2014, para retomar aos 7,38 de 2006. Assim, de 2014 a 2017 a nota da democracia brasileira caiu 0,52 ponto, atingindo a pior avaliação desde que o ranking da democracia começou a ser elaborado, em 2006, com uma nota que o coloca atrás de países como o Uruguai $(8,12)$ a Costa Rica $(7,88)$, o Chile $(7,84)$, a Jamaica $(7,29)$ e a Argentina $(6,96)$, entre outros.

Tabela 3 - Países mais bem colocados no ranking da democracia

\begin{tabular}{c|c|c} 
Posição & País & Pontuação \\
\hline 1 & Noruega & 9,89 \\
\hline 2 & Islândia & 9,58 \\
\hline 3 & Suécia & 9,39 \\
\hline $4-48$ & 45 países & - \\
\hline 49 & Brasil & 6,86
\end{tabular}

Fonte: Adaptado de THE ECONOMIST, 2017.

\subsection{Variáveis em que o Brasil é uma Democracia de Fato e Variáveis em que o Brasil Sequer é Considerado Democrático}

Em referência à primeira variável, Pluralismo e processo eleitoral, a nota da falha democracia brasileira é idêntica à da Suécia, uma democracia completa, conforme Tabela 4.

Tabela 4 - Variáveis utilizadas pelo ranking da democracia e a nota obtida em cada uma delas pelos três países mais bem colocados no ranking e pelo Brasil

\begin{tabular}{lcccc} 
Variáveis/País & Noruega & Islândia & Suécia & Brasil \\
\hline I. Pluralismo e processo eleitoral & 10,00 & 10,00 & 9,58 & 9,58 \\
II. Liberdades Civis & 9,71 & 9,71 & 9,41 & 8,24 \\
III. Funcionamento do Governo & 9,64 & 9,29 & 9,64 & 5,36 \\
IV. Participação Política & 10,00 & 8,89 & 8,33 & 6,11 \\
V. Cultura Política & 10,00 & 10,00 & 10,00 & 5,00
\end{tabular}

Fonte: Adaptado de THE ECONOMIST, 2017.

No que se refere ao Pluralismo Político, o Brasil é um país com mais de 30 partidos políticos registrados no Tribunal Superior Eleitoral, com pelo menos 21 deles possuindo assento no Congresso Federal, tendo pelo menos 3 representantes cada. No que se refere ao processo eleitoral, desde o ano de 2000 todas as eleições são realizadas eletronicamente, em um sistema seguro, sendo parte ainda do processo eleitoral um sistema eletrônico no qual as contas apresentadas pelos candidatos, partidos e campanhas podem ser acompanhadas. Isso sem contar os procedimentos perante o Tribunal Superior Eleitoral para discussão quanto ao registro de candidaturas ou impugnações e cassação de candidatos que se encontravam inelegíveis, tudo devidamente regido por um Código de Leis Eleitorais e leis específicas, como a Lei no 9.504 de 1997. 
A alta nota obtida pelo Brasil em relação ao item I é algo que se extrai não apenas da existência de uma questão constitucional ou da existência de procedimentos legislativos-eleitorais de natureza democrática, mas principalmente da existência de reflexos práticos vindos da sociedade, de onde se diagnostica que este pilar se concretiza no mundo real e não apenas no mundo das leis.

A categoria II, liberdades civis, também conhecida como liberdades e garantias individuais, embora apresente uma distância de 1,17 pontos entre o Brasil e a Suécia, é uma outra categoria que, pela nota brasileira, individualmente considerada, poderia classificar o país como uma democracia completa.

Esta nota, somada à obtida na categoria I. pluralismo e processo eleitoral, situaria o Brasil, se fossem as únicas consideradas, com uma nota média de 8,91, o que seria suficiente para situar o país entre os dez primeiros colocados do ranking da democracia, em termos de democracias completas, à frente de países como a Alemanha, o Reino Unido, a Áustria, o Uruguai e a Espanha, entre outros.

Este item refere-se às liberdades e garantias individuais, tema constitucional, previsto no título II da Carta Magna e que encontra reflexos sociais concretos que extrapolam o texto constitucional chegando, de fato, à vida social, como pode ser percebido em diversas decisões do Supremo Tribunal Federal, ${ }^{22}$ que atingem, diretamente, a sociedade civil. Exemplos disso são a ADI 4.277 e a ADPF $132,{ }^{23}$ em que se percebe a proteção que a corte constitucional confere aos cidadãos contra a interferência do Estado, para a celebração do casamento religioso com efeitos civis, sobre a escolha daqueles que se casam.

Aqui, o Supremo Tribunal Federal aponta que uma lei federal que poderia ser interpretada de forma preconceituosa, discriminatória ou atentatória a direitos básicos, deve ser interpretada "conforme a Constituição", definindo-se, assim, que a concreta realização dos ideais constitucionais não coaduna com a mera possibilidade de se interpretar uma norma de forma discriminatória. Este entendimento do Supremo Tribunal Federal permite a formulação da hipótese de que os direitos não se autoefetivam, sendo necessário, além da proteção contra os arbítrios estatais, o estabelecimento de ferramentas que permitam ao cidadão, diante da possibilidade do abuso de poder ou desrespeito a "direito líquido e certo", buscar a efetivação dos seus direitos ou o afastamento de ameaça a eles, o que se convencionou chamar Remédios Constitucionais (Habeas Corpus, Habeas Data, Mandado de Segurança, Mandado de Injunção, Ação Popular e Ação Civil Pública), por serem instrumentos aptos a salvaguardar a adequada aplicação constitucional.

Neste ponto o STF trabalha com o intuito de mitigar a ausência de representatividade de grupos minoritários na formação da vontade política da nação, de forma que o STF se antecipa a eventuais condutas discriminatórias vedando-as para o caso da autonomia pública - apontada por Habermas - não conseguir efetivar-se, como no caso de grupos minoritários.

É possível concluir que, formalmente, existem 75 incisos, 24 alíneas e 4 parágrafos constitucionais referentes a direitos básicos, ou garantias fundamentais, dando conta da existência de um grande arcabouço de direitos formais que, quando não efetivados ou sob ameaça encontram uma gama de ações e procedimentos a serem manejados em seu socorro, procedimentos estes que são efetivamente utilizados na prática, em números crescentes, concretizando, em termos fáticos, as propostas deste pilar democrático.

\footnotetext{
22Ver STF: [ADI 3.510, rel. min. Ayres Britto, j. 29-5-2008, P, DJE de 28-5-2010.],

[ADI 3.330, rel. min. Ayres Britto, j. 3-5-2012, P, DJE de 22-3-2013.],

[ADPF 186, rel. min. Ricardo Lewandowski, j. 26-4-2012, P, DJE de 20-10-2014.]

${ }^{23}$ Ver STF: [ADI 4.277 e ADPF 132, rel. min. Ayres Britto, j. 5-5-2011, P, DJE de 14-10-2011.]
}

O sexo das pessoas, salvo disposição constitucional expressa ou implícita em sentido contrário, não se presta como fator de desigualação jurídica. Proibição de preconceito, à luz do inciso IV do art. 3ㅇ da CF, por colidir frontalmente com o objetivo constitucional de "promover o bem de todos". Silêncio normativo da Carta Magna a respeito do concreto uso do sexo dos indivíduos como saque da kelseniana "norma geral negativa", segundo a qual "o que não estiver juridicamente proibido, ou obrigado, está juridicamente permitido". (...) Ante a possibilidade de interpretação em sentido preconceituoso ou discriminatório do art. 1.723 do CC, não resolúvel à luz dele próprio, faz-se necessária a utilização da técnica de "interpretação conforme a Constituição". Isso para excluir do dispositivo em causa qualquer significado que impeça o reconhecimento da união contínua, pública e duradoura entre pessoas do mesmo sexo como família. Reconhecimento que é de ser feito segundo as mesmas regras e com as mesmas consequências da união estável heteroafetiva [ADI 4.277 e ADPF 132, rel. min. Ayres Britto, j. 5-5-2011, P, DJE de 14-10-2011.] 
Nos três critérios faltantes, aqueles que puxam a média da nota brasileira para baixo, situando esta como uma democracia falha, temos: (III) funcionamento do governo, 5,36, que classificaria o país como um regime híbrido; (IV) participação política, 6,11, que classificaria o Brasil como uma democracia falha, e (V) cultura política 5,00, classificando o Brasil como um regime híbrido.

A média destas notas colocaria o Brasil, como um regime híbrido, com 5,49 pontos, e a razão, como já se pode prever pela leitura dos tópicos anteriores, é que esses elementos, embora possam se encontrar legalmente previstos, não se realizam na prática.

Iniciando pelo item III - funcionamento do governo - utilizaremos a segunda pesquisa empírica, esta com foco na América Latina, intitulada Latinobarómetro 2017, que identificou a satisfação com a democra$\mathrm{cia},{ }^{24}$ relacionando-a com uma variável objetiva sobre o desempenho do governo.

Assim, no tópico de satisfação com a democracia, o Brasil é o último colocado do Latinobarómetro 2017, com apenas 13\% dos entrevistados declarando estarem satisfeitos com o desempenho do governo, com o seu funcionamento e com a sua condução. Para que se possa comparar, a média da América Latina foi de $30 \%$ de satisfeitos e o país mais bem colocado, com $57 \%$ de satisfeitos, foi o Uruguai, mais bem colocado também no índex da democracia do The Economist, o que demonstra certa sintonia entre os dois conjuntos de dados empíricos sobre a democracia.

O item III, funcionamento do governo, é interpretado pelo Latinobarómetro 2017 como "para quién se gobierna", com o objetivo de entender a orientação dada ao governo de um país. Desta forma, caso o governo não seja orientado para os interesses da coletividade, mas de poucos, não poderá funcionar adequadamente, por ser, desta forma, o produto de algo que não deve encontrar guarida no governo, que por sua vez deve representar a vontade do povo:

Quando a pergunta feita é no sentido de entender se o país encontra-se governado para o bem do povo ou para o interesse de alguns poucos, o Brasil volta a assumir a dianteira em toda a América Latina, com $97 \%$ dos entrevistados acreditando que neste país se governa para o interesse de alguns poucos (LATINOBARÓMETRO, 2018, p. 18).

Finalmente, para que se possa concluir que a nota brasileira, obtida no ranking da democracia, é até boa diante da percepção do seu povo sobre a existência concreta ou materializada de um governo funcionando a seu serviço, tem-se na categoria "aprovação do governo", em que o país com apenas $6 \%$ dos entrevistados aprovando o governo local, 11 pontos percentuais atrás do penúltimo colocado, El Salvador, com 17\% de aprovação (LATINOBARÓMETRO, 2018, p. 18). Pode-se concluir então, por estes dados empíricos, que o item III, funcionamento do governo, não se realiza, no Brasil, de forma prática e perceptível ao cidadão.

Em continuidade, evoluímos para o item IV, participação política, em que o Brasil recebeu a nota 6,11 no ranking da democracia. Este item trata de um direito-dever no Brasil, constitucionalmente expresso, que cria uma obrigação constitucional de votar a todos os maiores de 18 anos. ${ }^{25}$ Diante desta obrigatoriedade, a eleição nacional ocorrida no Brasil em 2014, por exemplo, teve em seu segundo turno 30.138.167 eleitores ausentes e, dos que compareceram, 1.921.819 votaram em branco e 5.219.787 anularam seus votos. Dessa forma, mais de 37 milhões de cidadãos em condição de votar preferiram por algum motivo não escolher qualquer candidato (BRASIL, 2018f).

\footnotetext{
24“Podemos decir que la evidencia indica que son los factores políticos que conducen estos indicadores a una caída mucho más que los económicos. (...)

La satisfacción con la democracia está altamente correlacionada con la aprobación de gobierno porque es una variable de desempeño, se diferencia del apoyo a la democracia que implica el apoyo al tipo de régimen. Es por ello que la satisfacción es un indicador que muestra mucho más sensible y que muestra mucha más variación año a año que el indicador de régimen político" (LATINOBARÓMETRO, 2018, p. 16-17).

${ }^{25} \mathrm{Art}$. 14. A soberania popular será exercida pelo sufrágio universal e pelo voto direto e secreto, com valor igual para todos, e, nos termos da lei, mediante:

(...)

$\S 100$ alistamento eleitoral e o voto são:

I-obrigatórios para os maiores de dezoito anos;

II - facultativos para: a) os analfabetos; b) os maiores de setenta anos; c) os maiores de dezesseis e menores de dezoito anos.
} 
Acerca da opinião do cidadão sobre este processo de participação, $67 \%$ dos brasileiros entrevistados afirmam acreditar que o seu voto é realmente secreto e que não pode ser conhecido por partidos ou governos, o que equivale a dizer que um total de $33 \%$ dos eleitores entrevistados não confiam na instituição do voto secreto, o que representa uma grave ameaça aos procedimentos de natureza democrática (LATINOBARÓMETRO, 2018, p. 40).

A participação política, por óbvio, não se restringe ao processo eleitoral, no entanto a ausência de participação neste quesito faz com que o brasileiro não conheça e assim não consiga identificar e diferenciar os agentes políticos, podendo, por fatores como ausência de informações confiáveis, tornar-se uma espécie de analfabeto político, o que o afasta, por raciocínio lógico, do cenário político, tornando-o menos engajado politicamente (CARNEIRO; TORRES; EKMAN, 2017).

No que se refere ao item faltante (V) cultura política, este claramente não é parte da cultura brasileira, uma vez que apenas 43\% dos brasileiros entrevistados pelo Latinobarómetro 2017 demonstraram apoiar a democracia, um número 11 pontos percentuais maior do que em 2016, quando 32\% afirmavam apoiar a democracia como forma de organização do poder político, mas 12 pontos menor do que em 2015, quando 54\% dos brasileiros entrevistados afirmaram apoiar a democracia, número este apenas um ponto menor do que o maior percentual já atingido pelo Brasil nesta categoria, no ano de 2009, quando 55\% das pessoas entrevistadas declararam apoiar a democracia (LATINOBARÓMETRO, 2018, p. 12-13).

Quando questionados sobre o grau de democracia, os entrevistados foram convidados a classificar o seu país em uma escala de 1 a 10, em que 1 é não democrático e 10 é totalmente democrático. 0 Brasil foi classificado, juntamente com El Salvador, como o país com "menos democracia", na posição 4.4 na escala em que a média da América Latina foi 5.5. Apenas a título de comparação, o ranking da democracia conferiu ao Brasil 6,86 pontos e a El Salvador, 6,43, colocando ambos como democracias falhas, de forma que a percepção pessoal do indivíduo não fica muito distante daquela formal e metodologicamente estabelecida.

\section{CONCLUSÃO}

A reconciliação construída por Habermas para as ideias de soberania popular e Estado de Direito por meio do princípio democrático permite a conclusão de que o Estado Democrático de Direito não apenas prescreve procedimentos de natureza democrática, uma vez que isso é insuficiente para assegurar o exercício das autonomias públicas e privadas do indivíduo.

O Estado Democrático de Direito configura-se no cenário em que os indivíduos podem, por si, construir o ambiente em que viverão, por meio de procedimentos democráticos. Nesse sentido, o fim ou télos da democracia não é a existência de procedimentos democráticos, mas de um ambiente social em que o princípio constitucionalmente previsto ultrapassa as páginas do texto legal concretizando-se na vida real dos cidadãos.

A reconciliação proposta por Habermas permite que a vida em uma sociedade democrática seja analisada, por si, como um direito básico de todo cidadão, direito este que possibilita a construção, efetivação e proteção de tantos outros direitos quantos se fizerem necessários.

O télos democrático é a construção de nações democráticas e não de procedimentos democráticos, que podem, no máximo, ser recebidos como instrumento para o estabelecimento de sociedades democráticas. Isso, no entanto, não será feito exclusivamente por meio de um procedimento, mas por um atuar, de fato democrático por parte dos cidadãos aptos a construir essa nação.

Finalmente, percebe-se que a construção de um Brasil democrático, de fato, é responsabilidade daqueles que no país vivem, estabelecendo o agir democrático como uma prática cotidiana .Isso ocorre posto que, de direito, o país já se encontra classificado como democrático. Falta, no entanto, que esta democracia de direito concretize, a partir do agir democrático dos cidadãos, uma democracia completa. Esta construção, porém, não será atingida por meio de procedimentos democráticos, que já existem e encontram-se consolidados no Brasil, pois como visto, uma democracia de direito precisa concretizar instituições e práticas sociais de natureza democrática para que possa ser vista como uma democracia de fato e posteriormente como uma democracia completa. 


\section{REFERÊNCIAS}

BAXTER, H. Habermas: The Discourse Theory of Law and Democracy. EUA: Stanford University Press, 2011. 340p.

BBC NEWS. How Brazil has put an 'e' in vote. Disponível em: <http://news.bbc.co.uk/2/hi/7644751.stm>. Acesso em: 10 dez. 2017 e 1 으 mar. 2018.

BERGER, Peter; NEUHAUS, Richard. To Empower People. From State to Civil Society. Washington: American Enterprise Institute, 1977.

BRASIL. Constituição Federal de 1988. Disponível em: <http://www.planalto.gov.br/ccivil_03/constituicao/constituicao.htm>. Acesso em: 1ㅇ maio 2018a.

. Tribunal Superior Eleitoral. [on-line]. Disponível em: <http://www.tse.jus.br/partidos/partidos-politicos/registrados-no-tse>. Acesso em: 2 fev. 2018b.

Supremo Tribunal Federal. ADI 4.277 e ADPF 132. Relator: Ministro Ayres Britto. 14/10/2011. Disponível em: <WWW. stf.jus.br/portal/constituicao/artigoBd.asp?item=31> Aceso em: 2 fev. 2018c.

. Superior Tribunal de Justiça. [on-line] Disponível em: <http://www.stj.jus.br/internet_docs/jurisprudencia/ jurisprudenciaemteses/Jurisprudência\%20em\%20teses\%2036\%20-\%20Habeas\%20Corpus.pdf>. Acesso em: 2 fev. 2018d. . Superior Tribunal de Justiça. [on-line]. Disponível em: <http://www.stj.jus.br/internet_docs/jurisprudencia/

jurisprudenciaemteses/Jurisprudência\%20em\%20teses\%2091\%20-\%20Mandado\%20de\%20Segurança\%20-\%20III.pdf>. Acesso em: 2 fev. 2018e.

. Tribunal Superior Eleitoral. [on-line] Disponível em: <http://www.tse.jus.br/eleitor-e-eleicoes/eleicoes/eleicoes-anteriores/eleicoes-2016/prestacao-de-contas>. Acesso em: 2 fev. $2018 f$.

Câmara dos Deputados. [on-line]. Disponível em: <http://www.camara.leg.br/Internet/Deputado/bancada.

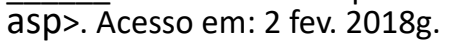

CARNEIRO, Thiago Lopes; TORRES, Claudio Vaz; EKMAN, Joakim. Political Participation in Brazil and Sweden: The Role of Stereotypes and Contagion. Psicologia: Teoria e Pesquisa, Brasília, v. 32, mar. 2017. Disponível em: <http://www.scielo.br/scielo. php?script=sci_arttext\&pid=S0102-37722016000500222\&lng=pt\&tlng=pt>. Acesso em: 1ㅇ fev. 2018.

CONSULTOR JURÍDICO. Remédio na UTI aumento do uso de HC divide opiniões. Disponível em: <https://www.conjur.com.br/ 2011-abr-01/juizes-criticam-aumento-hcs-advogados-defendem-ferramenta>. Acesso em: 2 mar. 2018.

CROSBY, Ned. In search of the competent citizen. Working Paper. Plymouth: Center for New Democratic Processes, 1975.

DIENEL, Peter. Techniken bürgerschaftlicher Beteiligung an Planungsprozessen. Offene Welt, 101, 1970.

FISHER, Robert. Grass-roots organizing worldwide; common ground, historical roots, and tension between democracy and the State. In: FISHER, Robert; KLING, Joseph (Dir.). Mobilizing the Community. Local Politics in the Era of the Global City. Urban Affairs Annual Review, Newbury Park; London; New Delhi: Sage Publication, n. 41, 1993.

HABERMAS, Jürgen. Théorie de l'agir communicationnel. Paris: Fayard, 1987.

. Human Rights and Popular Sovereignty: the liberal and republican versions - lecture given at the Philosophy Department of North-Western University on September 2. Ratio Juris, Oxford, UK, v. 7, n. 1, p. 1-13, mar. 1994.

1996.

Between Facts and Norms: contributions to a discourse theory of law and democracy. Massachussets: MIT Press,

. Law as medium and law as institution: Dillemas of Law in the welfare state. Trad. lan Fraser e Constance Meldrum. Berlim: European Institute, 1985. p. 203-220.

20, jan. 1995.

On the Internal Relation between the Rule of Law and Democracy. European Journal of Philosophy, Oxford, UK, p. 12-

The theory of communicative action. Lifeworld and system: a critique of functionalist reason. Tradução Thomas Mc$\overline{\text { Carthy }}$ (1987). Boston: Beacon Press, 1986. V. 2.

Loyola, 2002.

A inclusão do outro: estudos de teoria política. Tradução George Sperber e Paulo Astor Soethe. São Paulo: Edições . Direito e Democracia: entre facticidade e validade, volume 2. Tradução Flávio Beno Siebeneichler. Rio de Janeiro: Tempo Brasileiro, 1997.

HOROWITZ, Irving Louis. "The Struggle for Democracy." The National Interest, n. 83 (2006), p. 114-120. Disponível em: http:// www.jstor.org/stable/42897611. Acesso em: 2 fev. 2018.

LATINOBARÓMETRO: OPINIÓN PUBLICA LATINOAMERICANA. Banco de datos. Disponível em: <http://www.latinobarometro. org/latcontents.jsp>. Acesso em: 12 fev. 2018.

PATEMAN, Carole. Participation and democratic theory. London: Cambridge University Press, 1970.

RAWLS, John. A theory of justice. Cambridge, Mass.: The Belknap Press of Harvard University Press, 1971.

THE CONSTITUTE PROJECT. Constitute, the world's constitute to read, search and compare. Disponível em: <https://www.constituteproject.org/?lang=en>. Acesso em: 10 fev. 2018.

THE ECONOMIST. Intelligence Unit. Democracy index 2017 free speech under attack. Disponível em: <http://pages.eiu.com/rs/ 753-riq-438/images/democracy_index_2017.pdf?mkt_tok=eyjpijoitnpkbe9usmlnv0zttm1jmiisinqioijpvgdrqwfou2fcl3pobghyzkjuwtu5nvl1d0ppv0p2smf3wljfzkdpqwxuewjvm0juk0zsdzlpv241vvzyvlh2n3htdzrmwwninu8xandluuhxc1zynzvrstdoz3djmxm3qjfkskj0s2n>. Acesso em: 5 fev. 2018. 